\title{
Studies of the performance of nanostructured and other compatible consolidation products for historical renders
}

\author{
G. Borsoi ${ }^{1, a}, M$. Tavares ${ }^{1, b}$, R. Veiga ${ }^{1, c}$, A. Santos Silva ${ }^{1, d}$ \\ ${ }^{1}$ Laboratório Nacional de Engenharia Civil, Lisbon, Portugal

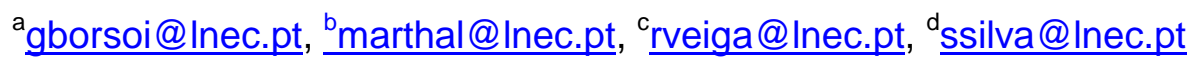

Keywords: Historical renders, Consolidation products, Compatibility

\begin{abstract}
This work is inserted in a wider project aiming at the conservation and durability of historical renders, through compatibles techniques and materials; in particular the restitution of cohesion of historical renders, turned friable by the loss of binder due to physical or chemical actions, is studied. Surface consolidation, directed to restore cohesion and stability, is based on the use of materials with aggregating properties. This operation is reached usually through the application of organic or mineral consolidants, but inorganic consolidants (such as calcium hydroxide or ethyl silicate) are becoming preferred due to better compatibility and durability.

Based on the results of previous studies, two mineral compatible products were selected for the first phase of tests: a commercial suspension of nanoparticles of calcium hydroxide in propanol (Nanorestore); a silicate product, consisting on a limewater dispersion of ethyl silicate.

Consolidation products were than applied on different mortars samples previously prepared, in order to assess their efficacy by determining their physical, mechanical and microstructural properties before and after the consolidation treatment.

Mechanical and physical analyses were performed, such as compression and flexural strenght and superficial hardness. Microstructural and chemical analyses of the consolidation product and of the consolidated samples are also reported.
\end{abstract}

\section{Introduction}

A common degradation phenomenon in mortars is the loss of cohesion of the binder-aggregate system, which is usually followed by the alteration of the visual aspect, deposition and formation of new products, and finally loss of mechanical strenght and thus of material from the surface.

The loss of cohesion can happen by the cumulative effects of mechanical deformation processes, due to hygrothermal variations along the years, related to the environment (rain, humidity variations, temperature, wind, pollutants agents); or as a consequence of a group of chemical and biological phenomena that can modify the nature of the binder [1].

The restitution of cohesion between particles of a mortar, turned friable by the loss of binder, is reached usually through the application of organic or mineral consolidants. Since the $19^{\text {th }}$ century inorganic products such as silicates, fluorides, barite and limewater were used [2], and in the $20^{\text {th }}$ century polymers (silicon resins, acrylics and epoxy resins) were experimented.

Inorganic consolidants are becoming preferred due to better compatibility and durability. The best known inorganic consolidants are calcium hydroxide (limewater), barium hydroxide, ethyl silicate, calcium oxalate and calcium tartrate.

The aim of this work is the experimental characterization of two different consolidant products, namely a traditional compatible product such as limewater, mixed with ethyl silicate, and a commercial alcoholic dispersion of nanoparticles of calcium hydroxide, an innovative consolidant product. The characterization of these products was carried out and their effect on damaged mortars was evaluated through tests on specimens before and after treatment. Test methods have been developed, using weak mortars to simulate degradation. The two consolidant products were then applied on weak mortar specimens and the evolution of their effect was accompanied and periodically evaluated. 


\section{Materials}

\section{Specimens - Mortar samples preparation}

Different mortar specimens were prepared, varying the binder/aggregate ratio from 1:8 to 1:3 (in volume) and the binder/aggregate ratio of 1:4 was chosen to get the desired effect of a low cohesion mortar without significant loss of material.

The aggregate used was a siliceous sand obtained from a mixture of 3 different calibrated sands with mean particle sizes $<2 \mathrm{~mm}$ (fig.1). The aim was to get a well graduated sand, similar to an average sand used on render mortars.

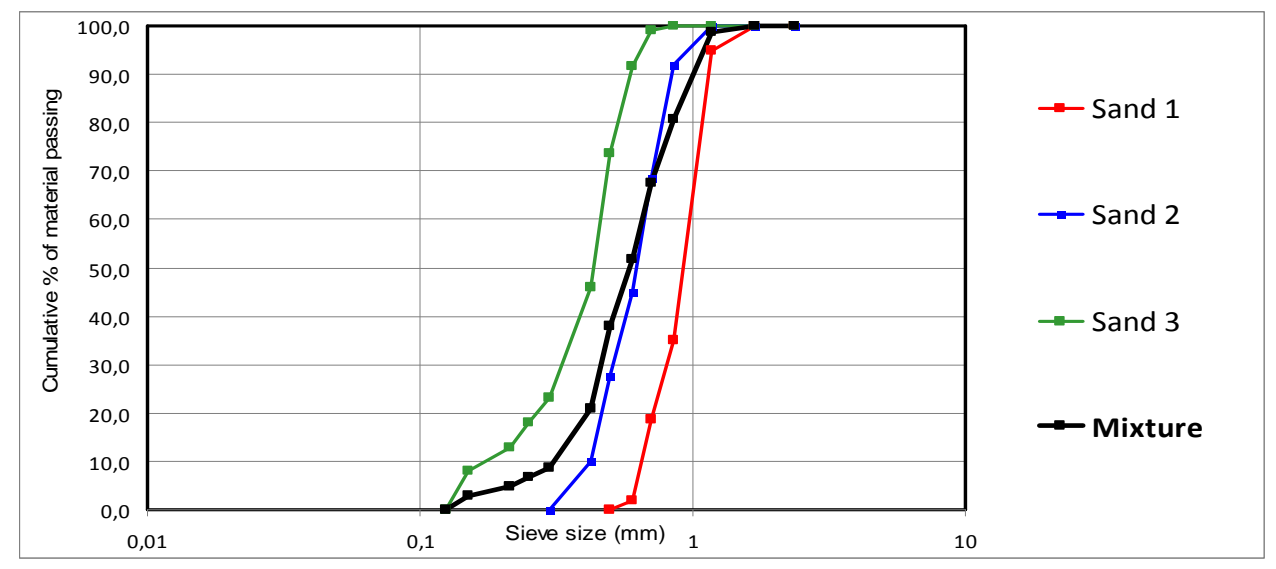

Fig. 1 - Grain size distribution of the different aggregates used.

After the optimization of the mortar composition, different samples were prepared, such as mortar prisms $(40 \times 40 \times 160 \mathrm{~mm})$ and ceramic bricks $(28 \times 19 \mathrm{~cm})$ and tiles $(16 \times 16 \mathrm{~cm})$ with a single mortar layer of $1,5 \mathrm{~cm}$ thickness.

\section{Consolidant materials and application on lime mortar specimens}

The effectiveness of limewater as consolidant is known and previous studies evidenced good results $[3,4,5]$, beyond economical advantage and full compatibility. However, limewater usually contains not more than $2 \mathrm{~g} / \mathrm{L}$ of calcium hydroxide, that only guarantee a low consolidation effect, with a poor cementing action [2], unless it is applied in a high number of cycles.

It was decided to explore the efficiency of an additivated limewater, matured in a closed bucket for some years, with a commercial ethyl silicate (Estel $1000^{\circledR}$, CTS), a product widely used in stone consolidation; after previous tests with different concentrations of ethyl silicate, it was decided to use a low concentration (5\%), in order to improve the penetration and to moderately increase the mechanical strength, so avoiding superficial micro-tension.

Nanolime dispersions of calcium hydroxide are white to opal products containing stable calcium hydroxide nanoparticles dispersed in an alcoholic medium, usually isopropanol. According to the producers (Nanorestore $\left.{ }^{\circledR}, \mathrm{CTS}\right)$, the $\mathrm{Ca}(\mathrm{OH})_{2}$ have a hexagonal shaped form and a size range between 50 and $600 \mathrm{~nm}[6,7]$; this very small size permits a highly active surface and high reactivity and carbonation rate. Besides, the reduced dimension of $\mathrm{Ca}(\mathrm{OH})_{2}$ guarantees a deeper penetration inside the smaller pores.

Recent studies had evidenced the potential of nanolime dispersions, such as the high penetration depth, the full compatibility, and the high stability of the suspension $[8,9]$. This product can avoid problems related to reduced penetration depth, low binder content (due to the low solubility of lime) and incomplete carbonation process (free portlandite particles on the surface).

An analysis of the selected consolidation products was done considering important characteristics linked to an optimal application, including: $\mathrm{pH}$, setting time and dry residue content (Table 1). Their application was carried out in a conditioned room, at $23^{\circ} \mathrm{C}$ and $50 \% \mathrm{HR}$, using the manual spraying technique from a distance of $20-30 \mathrm{~cm}[3,5]$. Each consolidant product was nebulised in ten consecutive applications on the specimen's surface. 
Tab. 1 - Consolidation products characteristics

\begin{tabular}{|c|c|c|c|}
\hline Consolidation product & pH & Dry residue(g/L) & Setting time (min) \\
\hline Limewater + Ethyl Silicate (5\%) & 9,2 & 3,51 & 20 \\
\hline Nanolime & 7,2 & 1,28 & 120 \\
\hline
\end{tabular}

\section{Methods - Characterization of the consolidant treatments}

The physical-mechanical tests were executed on the specimens before and after treatments (90 days from the consolidant product application); the evaluation of the efficacy of the consolidant treatments was carried out through the use of different analysis and tests.

The improvement of the mechanical resistance was checked through flexural and compressive strength (EN 1015:11) and durometer hardness (ISO 7619:1997 and ASTM D 2240).

The surfaces of mortar specimens were observed with an Olympus SZH stereoscopical microscope, before and after treatment, and images were recorded digitally.

Moreover polished cross-sections were prepared to be observed at scanning electron microscopy (SEM). These specimens were dried during 12 hours in a drying oven at $60^{\circ} \mathrm{C}$, being then vacuum impregnated with an epoxy resin (resin-hardener ratio 3:1, Logitech); the impregnated cross sections were finally polished manually with two abrasive solutions of $15 \mu \mathrm{m}$ and $9 \mu \mathrm{m} \mathrm{of} \mathrm{Al}_{2} \mathrm{O}_{3}$, and then with three diamond abrasive solutions $(6,3$ e $1 \mu \mathrm{m})$. The surface of the specimens was sputtered with a gold film, being the SEM observations performed on a Jeol JSM-6400 coupled with an Oxford energy dispersive spectrometer (EDS) x-ray detector.

\section{Results and discussion}

\section{Compressive and flexural strength}

Table 2 gives the flexural and compressive strength of untreated and treated prismatic specimens after 90 days from the treatment.

Tab. 2 - Mechanical strength results (average values and standard deviations)

\begin{tabular}{|c|c|c|c|}
\hline \multicolumn{2}{|r|}{ Specimens } & $\begin{array}{c}\text { Flexural Strength } \\
\left(\mathrm{N} / \mathrm{mm}^{2}\right)\end{array}$ & $\begin{array}{c}\text { Compressive Strength } \\
\left(\mathrm{N} / \mathrm{mm}^{2}\right)\end{array}$ \\
\hline \multicolumn{2}{|r|}{ Untreated } & $0,24 \pm 0,03$ & $0,33 \pm 0,04$ \\
\hline \multirow{2}{*}{ Treated } & Lime water + Eth. Sil. 5\% & $0,37 \pm 0,03$ & $0,64 \pm 0,03$ \\
\hline & Nanolime & $0,30 \pm 0,01$ & $0,50 \pm 0,04$ \\
\hline
\end{tabular}

An increase of the mechanical strength is evident after treatment with both consolidants. The highest values were obtained with the application of limewater and ethyl silicate, with improvement of about $50 \%$ in the flexural strength and almost $100 \%$ in the compressive strength, compared to the untreated specimens. The results obtained with nanolime are lower compared to the specimens treated with limewater and ethyl silicate, but they nevertheless show an increase (about $25 \%$ in the flexural strength and 50\% in the compressive strength). According to the literature [1], it is required that a consolidation treatment would improve the flexural strenght, but without exceeding more than 1.5 times the values of untreated samples; a moderate improvement of the mechanical resistance is suitable, and this condition is satisfied in the case of both consolidant products used.

The penetration depth was verified through the use of a phenolphthalein agent (solution $1 \%$ of phenolphthalein in ethanol); the untreated specimens present a high and heterogeneous porosity, being verified that limewater with ethyl silicate $5 \%$ had a reduced penetration depth (1-4 mm). This product was concentrated on a superficial thin layer, while the nanolime had a greater penetration (2-6 $\mathrm{mm}$ ), probably due to the alcoholic solution $[3,5]$, which seems to allow a more homogeneous consolidation. 


\section{Durometer hardness (Shore A)}

The superficial hardness was verified through a durometer (Shore A), comparing the results obtained from untreated and treated mortars (90 days from the application of the product).

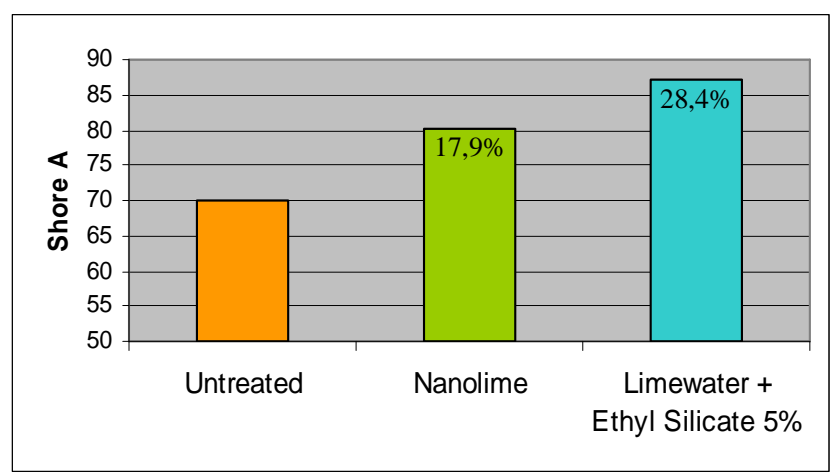

Fig. 2 - Evaluation of durometer hardness (Shore A)

An improvement of the superficial hardness of the treated specimens is evident. Treatment with nanolime presents a moderate increase of the superficial hardness (about 18\%) compared to the untreated specimens, while the treatment of limewater with ethyl silicate $(5 \%)$ registered a higher increase (almost 30\%), due to the formation of colloidal silica on the treated surface.

\section{Microscopical observations by stereozoom microscopy}

Stereozoom observations were made in order to evaluate the morphological and microstructural variations due to the consolidation treatments.

In comparison with the untreated specimens (fig. 3a), the specimens treated with a limewater dispersion of ethyl silicate (fig. 3b) show a more compact surface, with an evident decrease of the macroporosity. Otherwise this consolidant product seems to be concentrated in some areas, leaving others unconsolidated, forming a consolidant layer with planar aggregates and presenting a discontinuous distribution; the colloidal silica gel formed seems to interfere in the depth penetration of the consolidant, guarantying only a superficial consolidation.

On the other hand, a more uniform distribution of the consolidation product is evident in the specimens treated with nanolime (fig. 3c), which is not filling completely the pores but is more homogeneously distributed inside them; even if the reduced concentration of the nanoparticles of calcium hydroxides didn't induce a great improvement of the binder quantity, the nanolime permits a good penetration depth, with a slight reduction of the porosity.
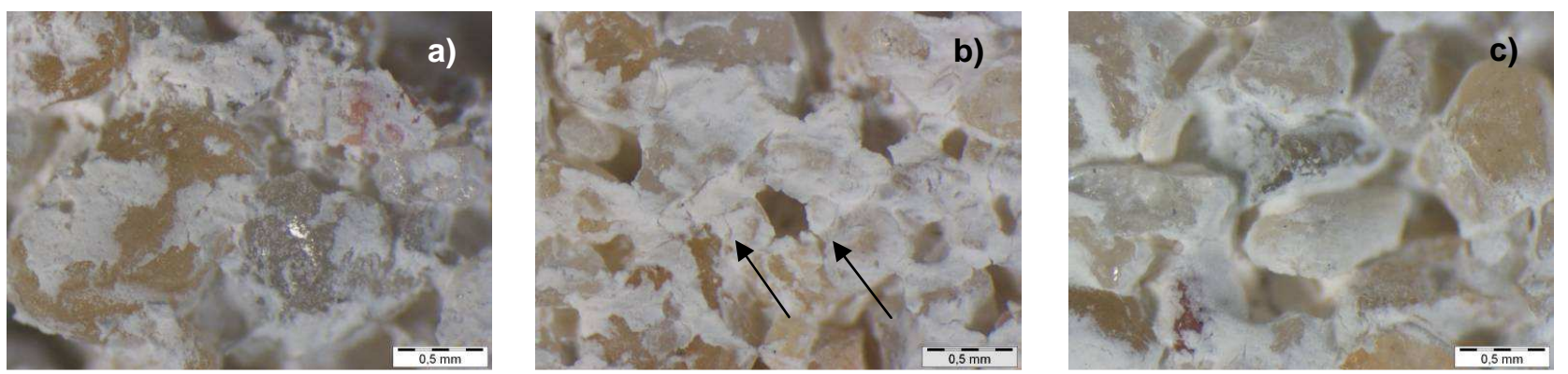

Fig. 3 - Stereozoom microphotograph (40x): a) Untreated specimen; b) Specimen treated with limewater dispersion of 5\% ethyl silicate and relative planar aggregates (arrows); c) Specimen treated with nanolime.

\section{Microstructural observations by SEM-EDS}

The results achieved with stereozoom observations were complemented with SEM-EDS analysis. The specimen treated with limewater with ethyl silicate shows the formation of platelike aggregates of colloidal silica. Indeed, the reaction of the silicate in the alkaline aqueous solution of limewater 
forms rapidly colloidal silica gel, which transforms itself in a xerogel due to the evaporation of the solvent; the presence of $\mathrm{CaCO}_{3}$ seems to modify the xerogel structure, inducing the development of shorter linear chains of tetrahedral silica and linear silicate structure, which can explain the rapid formation of a granular gel with a platelike shape [10].
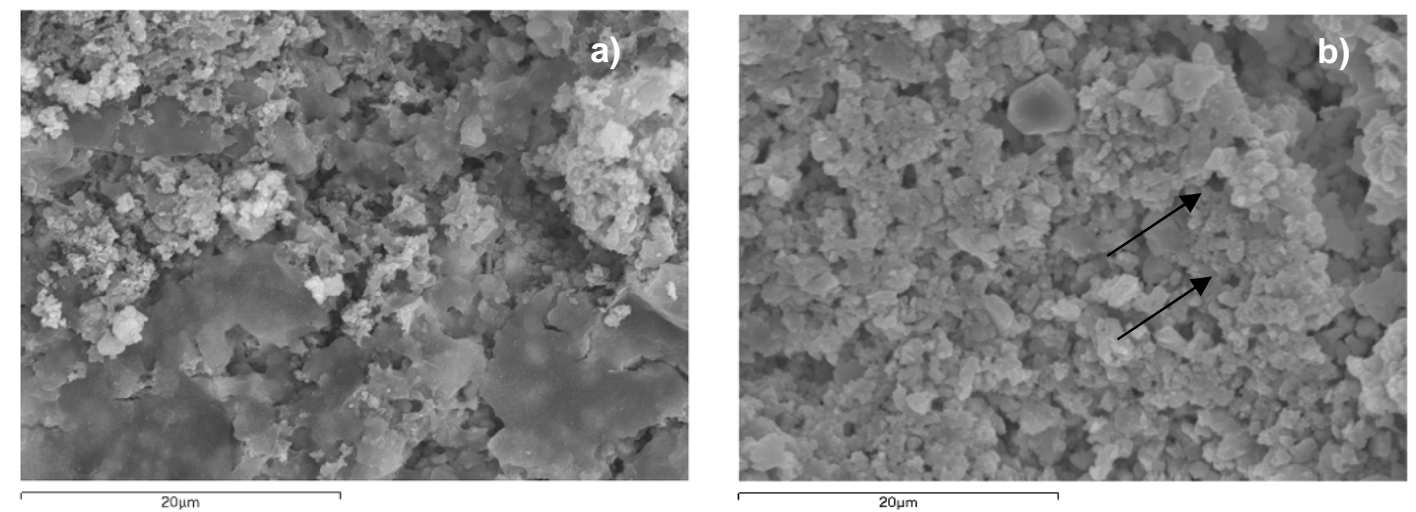

Fig. 4 - SEM/EDS images of the treated specimens: a) Presence of platelike shaped silica gel on the mortar surface treated with limewater-ethyl silicate dispersion; b) Homogeneous distribution of the clusters of nanoparticles in the mortar treated with nanolime dispersion.

The xerogels formed from the limewater-ethyl silicate show a vesicular microstructure, which could interacts chemically with the calcium carbonate and quartz particles, allowing a good reaggregating effect on the substrate and the restitution of the binder-aggregate cohesion.

The effect of the consolidation is evident on the mortar surface (fig. 4a), with filling of the pores, but the formation of planar aggregates can reduce the penetration depth of the consolidant product. Otherwise, mortars treated with the nanolime product show micro-sized calcitic clusters (fig. 4b), compact and polydispersed, formed from the aggregation of platelike nanolime particles; the distribution and morphology of these nanoparticles ensure a homogeneous consolidation film, embedded in the microcrystalline matrix of the original binder.

According to previous studies [11], the carbonation of nanolime particles originate oriented crystal grains, which promote the agglomeration of particles, improving the cementing action, the cohesion of the particles and thus the mechanical strength of the treated surface.

\section{Conclusions}

Two consolidation products, namely a limewater dispersion of ethyl silicate (5\%) and a commercial alcoholic dispersion of nanostructured calcium hydroxide, both with fully physical-chemical compatibility with lime-based mortars, were selected and applied on weak lime mortar samples.

The obtained results of the mechanical resistance, evaluated through durometer hardness and flexural and compressive strenght, evidenced some differences between the two products; the highest mechanical increase was obtained with the limewater dispersion of ethyl silicate, which however presented a reduced penetration depth, due to the rapid reaction of the ethyl silicate with limewater, forming platelike silica gels. Instead the alcoholic dispersion of nanolime particles, probably due to the reduced concentration of the nanostructured calcium hydroxide, guarantees a moderate improvement of the mechanical resistance, but shows an excellent penetration capacity, since the alcoholic solvent seems to improve the penetration of the nanostructured particles.

Microscopical and microstructural observation through stereozoom microscope and scanning electron microscopy evidence that the dispersion of ethyl silicate in limewater have consolidation effectiveness on the treated surface, due to the mixture of colloidal silica with the calcium carbonate obtained from the carbonation of the limewater; moreover calcium carbonate seems to interfere in the solidification of the xerogel formed from the ethyl silicate, promoting the development of planar structures and so of platelike aggregates of colloidal silica, reducing the penetration depth of the 
consolidant. However, due to the reduced depth penetration, this product is recommended only for mortars with superficial loss of cohesion.

Otherwise, nanolime particles permit a homogeneous distribution and better penetration on the treated substrate; the platelike nanoparticles present a specific crystallographic orientation that could contribute to an agglomeration process and so improve the cementing action and the mechanical resistance of the treated surface; moreover nanolime dispersion reduces partially the porosity, avoiding the occlusion of pores and maintaining the natural permeability to water vapour, without creating mechanical stress inside the treated mortar. Since this dispersion doesn't guarantee a high improvement of the mechanical resistance, the use of nanolime is recommended on mortars with reduced loss of cohesion, or in combination with other consolidation product.

Finally, interesting future prospective concern the combined application of the two analysed products, with higher concentration of calcium hydroxide nanoparticles.

\section{Acknowledgement}

This study was developed within a Project (Limencontech - Conservation and durability of historical renders: compatible techniques and materials) financed by FCT - Fundação para a Ciência e a Tecnologia (Portugal); special thanks goes to Paula Menezes for SEM-EDS analysis and to Bento Sabala and Ana Maria Duarte for mechanical tests.

\section{References}

[1] L. Toniolo, A. Paradisi, S. Goidanich, G. Pennati, Mechanical behaviour of lime based mortars after surface consolidation, Construction and Building Materials, Vol. 25, Issue 4 (2010) 1553-1559.

[2] E. Hansen, E. Doehne, J. Fidler, J. Larson, B. Martin, M. Matteini, C. Rodrigues-Navarro, E. Sebastian Pardo, P. Price, A. de Tagle, J.M. Teutonico, N. Weiss, A review of selected inorganic consolidants and protective treatment for porous calcareous materials, Reviews in Conservation, 4 (2003) 13-25.

[3] M. Tavares, R. Veiga, A. Fragata, Conservation of old renderings - The consolidation of renders with loss of cohesion. Proceeding of $1^{\text {st }}$ Historical Mortars Conference HMC08 Characterization, Diagnosis, Conservation, Repair and Compatibility, Lisbon (2008).

[4] M. Drdácký, Z. Slízkova, Calcium hydroxide based consolidation of lime mortars and stone, Proceeding of $1^{\text {st }}$ Historical Mortars Conference HMC08, Lisbon (2008).

[5] M. Tavares, Conservation and restoration of old renders. A methodology for their study and repair, PhD Thesis in Architecture by Technical University of Lisbon (2009).

[6] L. Dei, B. Salvadori, Nanotechnology in cultural heritage conservation: nanometric slaked lime saves architectonic and artistic surface from decay, Journal of cultural Heritage, 7 (2006) 110-115.

[7] R. Giorgi, L. Dei, P. Baglioni, A new method for consolidating wall paintings based on dispersions of lime in alcohol, Studies in Conservation, 45 (2000) 154-161.

[8] C. Moreau, Z. Slíkova, M. Drdácký, Strengthening of pure lime mortars with nanoparticles of calcium hydroxides, Proceeding of $2^{\text {nd }}$ Historic Mortars Conference HMC10 and RILEM TC 203-RHM Final Workshop, Prague (2010) 1113-1122.

[9] G. Ziegenbalg, K. Brümmer, J. Pianski, Nano-Lime - a new material for the consolidation and conservation for historical mortars, Proceeding of $2^{\text {nd }}$ Historic Mortars Conference HMC10 and RILEM 203 RHM Final Workshop, Prague (2010) 1301-1310.

[10] E. Zendri, G. Biscontin, I. Nardini, S. Rialto, Characterization and reactivity of silicatic consolidants, Construction and Building Materials, 21 (2007) 1098-1106.

[11] P. López-Arce, L.S. Gomez-Villalba, L. Pinho, M.E. Fernández-Valle, M. Álvarez de Buergo, Rand Fort R., Influence in the porosity and relative humidity on consolidation of dolostone with calcium hydroxide nanoparticles - effectiveness assessment with non-destructive techniques, Materials Characterization, 61 (2010) 168-184. 